\title{
Pessaries for POP and SUI: Their fitting, care, and effectiveness in various disorders
}

\author{
A refresher on how to fit a pessary, instructions for patients, goals \\ for pessary aftercare visits, and the various conditions for which pessaries \\ may or may not be effective
}

\author{
Henry M. Lerner, MD
}

\section{IN THIS ARTICLE}

Fitting

process

this page

Pessary

aftercare

page 23

Pessary

effectiveness

page 24 n Part 1 of this article in the December 2020 issue of $O B G$ Management, I discussed the reasons that pessaries are an effective treatment option for many women with pelvic organ prolapse (POP) and stress urinary incontinence (SUI) and provided details on the types of pessaries available.

In this article, I highlight the steps in fitting a pessary, pessary aftercare, and potential complications associated with pessary use. In addition, I discuss the effectiveness of pessary treatment for POP and SUI as well as for preterm labor prevention and defecatory disorders.

\section{The pessary fitting process}

For a given patient, the best size pessary is the smallest one that will not fall out. The only "rule" for fitting a pessary is that a woman's internal vaginal caliber should be wider than her introitus.

When fitting a pessary, goals include that the selected pessary:

\section{Dr. Lerner is Assistant Clinical Professor (retired),}

Harvard Medical School, Boston, Massachusetts.

The author reports no financial relationships relevant to this article.

doi: 10.12788 /obgm.0057
- should be comfortable for the patient to wear

- is not easily expelled

- does not interfere with urination or defecation

- does not cause vaginal irritation.

The presence or absence of a cervix or uterus does not affect pessary choice.

Most experts agree that the process for fitting the right size pessary is one of trial and error. As with fitting a contraceptive diaphragm, the clinician should perform a manual examination to estimate the integrity and width of the perineum and the depth of the vagina to roughly approximate the pessary size that might best fit. Using a set of "fitting pessaries," a pessary of the estimated size should be placed into the vagina and the fit evaluated as to whether the device is too big, too small, or appropriate. If the pessary is easily expelled, larger sizes should be tried until the pessary remains in place or the patient is uncomfortable. Once the pessary is in place, the clinician should be able to run his or her finger around the entire pessary; if this is not possible, the pessary is too tight. In addition, the pessary should remain more than one finger breadth above the introitus when the patient is standing or bearing down.

Since many patients who require a pessary are elderly, their perineal skin and 


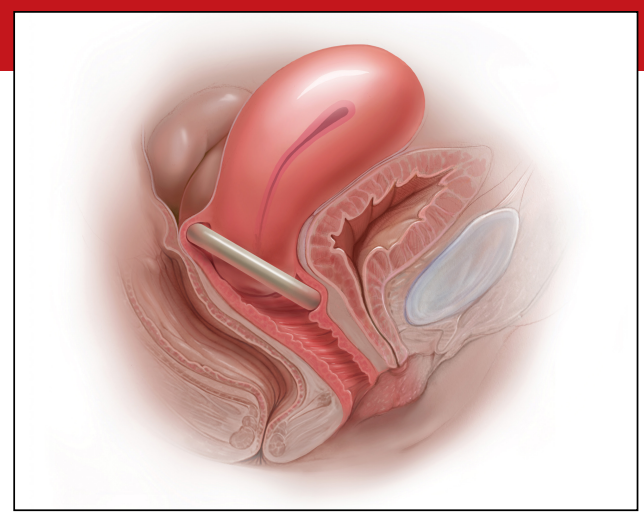

vaginal mucosa may be atrophic and fragile. Inserting a pessary can be uncomfortable and can cause abrasions or tears. Successfully fitting a pessary may require extra care under these circumstances. The following steps may help alleviate these difficulties:

- Explain the fitting process to the patient in detail.

- Employ lubrication liberally.

- Enlarge the introitus by applying gentle digital pressure on the posterior fourchette.

- Apply 2\% lidocaine ointment several minutes prior to pessary fitting to help decrease patient discomfort.

- Treat the patient for several weeks with vaginal estrogen cream before attempting to fit a pessary if severe vulvovaginal atrophy is present.

Once the type and size of the pessary are selected and a pessary is inserted, evaluate the patient with the pessary in place. Assess for the following:

Discomfort. Ask the patient if she feels discomfort with the pessary in position. A patient with a properly fitting pessary should not feel that it is in place. If she does feel discomfort initially, the discomfort will only increase with time and the issue should be addressed at that time.

Expulsion. Test to make certain that the pessary is not easily expelled from the vagina. Have the patient walk, cough, squat, and even jump if possible.

Urination. Have the patient urinate with the pessary in place. This tests for her ability to void while wearing the pessary and shows whether the contraction of pelvic muscles during voiding results in expulsion of the pessary. (Experience shows that it is best to do this with a plastic "hat" over the toilet so that if the pessary is expelled, it does not drop into the bowl.)

Re-examination. After these provocative tests, examine the patient again to ensure that the pessary has not slid out of place.

Depending on whether or not your office stocks pessaries, at this point the patient is either given the correct type and size of pessary or it is ordered for her. If the former, the patient should try placing it herself; if she is unable to, the clinician should place it for her. In either event, its position should be checked. If the pessary has to be ordered, the patient must schedule an appointment to return for pessary insertion.

Whether the pessary is supplied by the office or ordered, instruct the patient on how to insert and remove the pessary, how frequently to remove it for cleansing (see below), and signs to watch for, such as vaginal bleeding, inability to void or defecate, or pelvic pain.

It is advisable to schedule a subsequent visit for 2 to 3 weeks after initial pessary placement to assess how the patient is doing and to address any issues that have developed.

\section{Special circumstances}

It is safe for a patient with a pessary in place to undergo magnetic resonance imaging. ${ }^{1}$ Patients should be informed, however, that full body scans, such as at airports, will detect pessaries. Patients may need to obtain a physician's note to document that the pessary is a medical device.

Finally, several factors may prevent successful pessary fitting. These include prior pelvic surgery, obesity, short vaginal length (less than 6-7 cm), and a vaginal introitus width of greater than 4 finger breadths.
FAST

TRACK

Evaluate the patient with the pessary in place for discomfort, expulsion, and urination, and then re-examine to ensure that the pessary has not slid out of place 


\section{Pessaries for POP and SUI: Their fitting, care, and effectiveness in various disorders}

Ring pessary

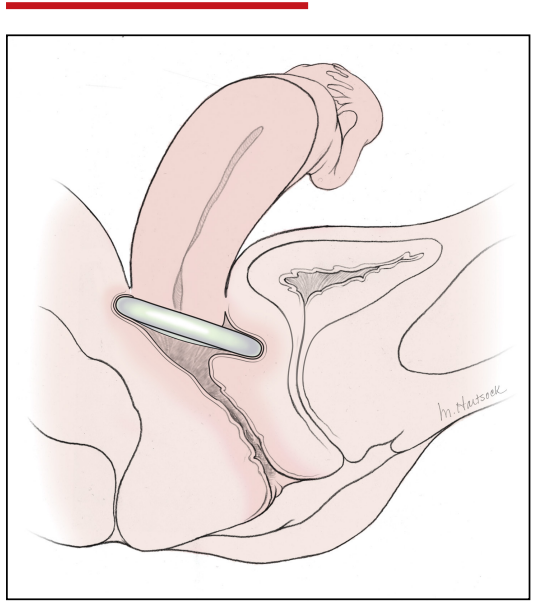

Gehrung pessary

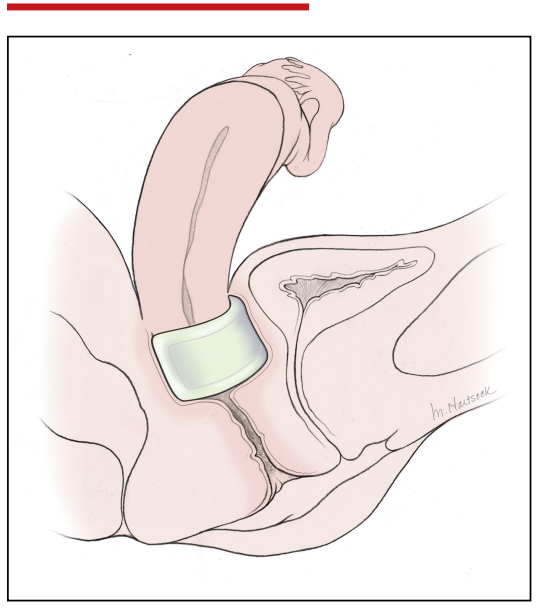

Donut pessary

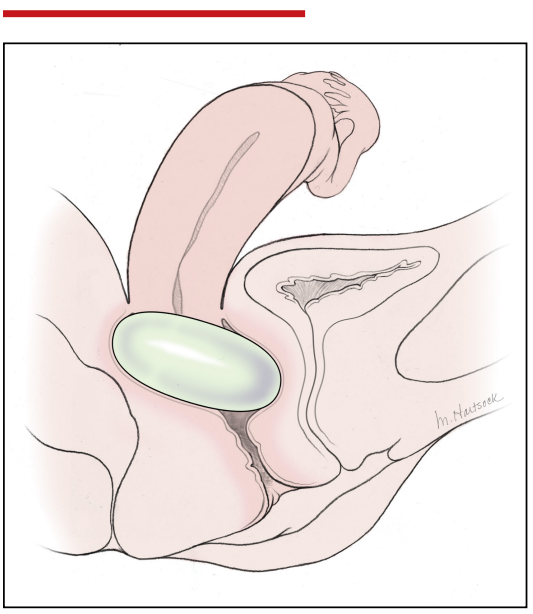

Marland pessary

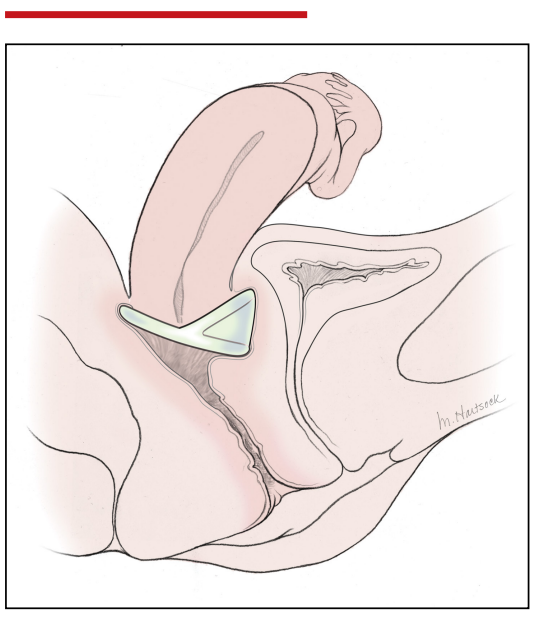

Gellhorn pessary

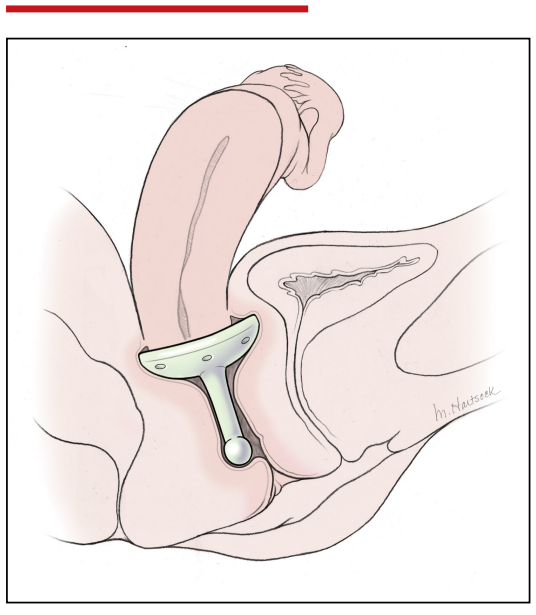

Inflatable pessary

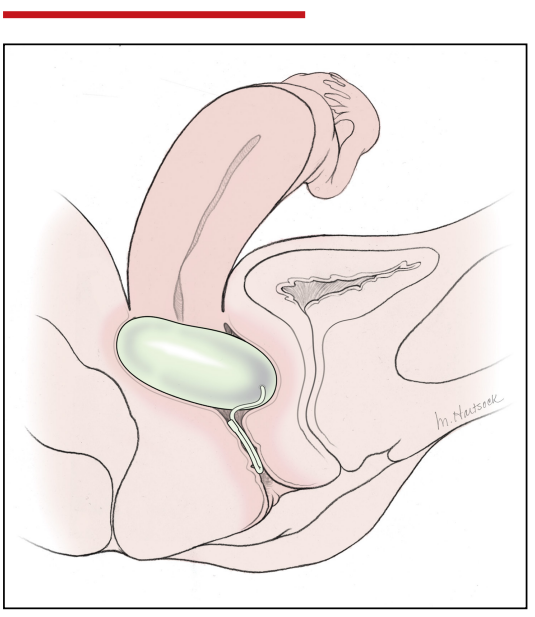

Shaatz pessary

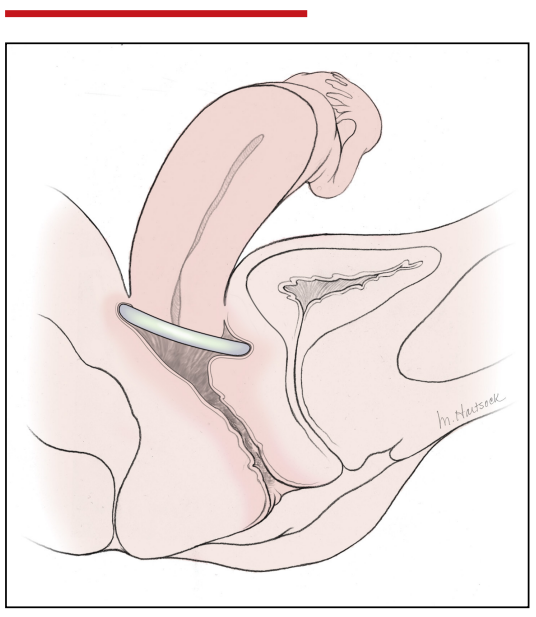

Cube pessary

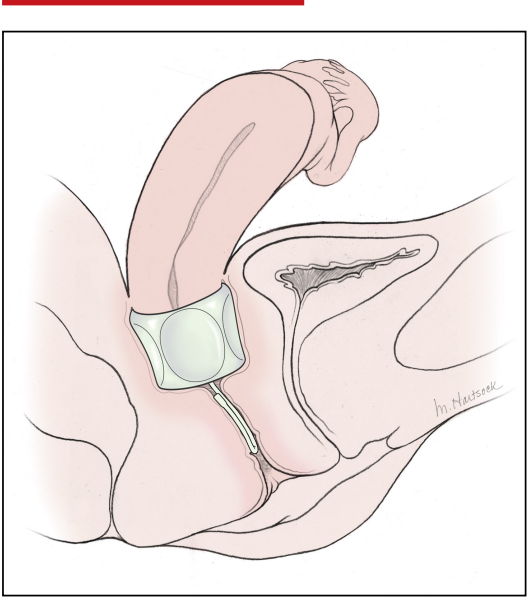

Lever pessary

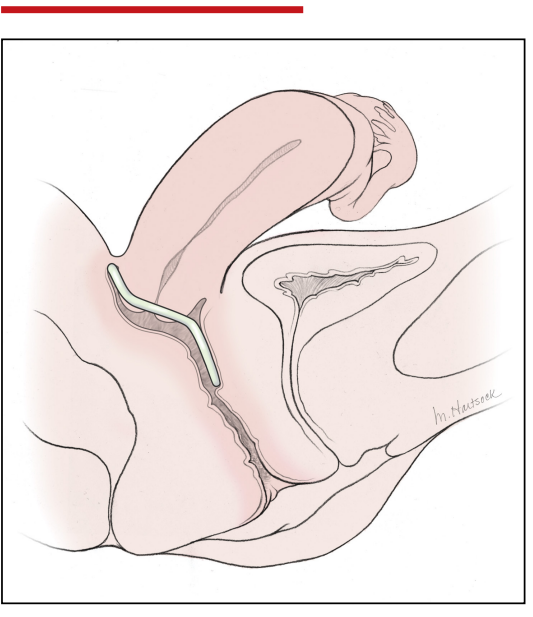




\section{Necessary pessary aftercare}

Once a pessary is in place and the patient is comfortable with it, the only maintenance necessary is the pessary's intermittent removal for cleansing and for evaluation of the vaginal mucosa for erosion and ulcerations. How frequently this should be done varies based on the type of pessary, the amount of discharge that a woman produces, whether or not an odor develops after prolonged wearing of the pessary, and whether or not the patient's vaginal mucosa has been abraded.

\section{The question of timing for pessary cleaning}

Although there are many opinions about how often pessaries should be removed and cleaned, no data in the literature support any specific interval. Pessaries that are easily removed by women themselves can be cleaned as frequently as desired, often on a weekly basis. The patient simply removes the pessary, washes it with soap and water, and reinserts it. For pessaries that are difficult to remove (such as the Gellhorn, cube, or donut) or for women who are physically unable to remove their own ring pessary, the clinician should remove and clean the pessary in the office every 3 to 6 months. It has been shown that there is no difference in complications from pessary use with either of these intervals. ${ }^{2}$

Prior to any vaginal surgical procedure, patients must be instructed to remove their pessary 10 to 14 days beforehand so that the surgeon can see the full extent of prolapse when making decisions about reconstruction and so that any vaginal mucosal erosions or abrasions have time to heal.

\section{Office visits for follow-up care}

The pessary "cleaning visit" has several goals, including to:

- see if the pessary is meeting the patient's needs in terms of resolving symptoms of prolapse and/or restoring urinary continence

- discuss with the patient any problems she may be having, such as pelvic discomfort or pressure, difficulty voiding or defecating, excessive vaginal discharge, or vaginal odor
- check for vaginal mucosal erosion or ulceration; such vaginal lesions often can be prevented by the prophylactic use of either estrogen vaginal cream twice weekly or the continuous use of an estradiol vaginal ring in addition to the pessary

- evaluate the condition of the pessary itself and clean it with soap and water.

\section{Potential complications of pessary use}

The most common complications experienced by pessary users are:

Odor or excessive discharge. Bacterial vaginosis (BV) occurs more frequently in women who use pessaries. The symptoms of BV can be minimized-but unfortunately not totally eliminated-by the prophylactic use of antiseptic vaginal creams or gels, such as metronidazole, clindamycin, Trimo-San (oxyquinoline sulfate and sodium lauryl sulfate), and others. Inserting the gel vaginally once a week can significantly reduce discharge and odor. ${ }^{3}$

\section{Vaginal mucosal erosion and ulceration.}

These are treated by removing the pessary for 2 weeks during which time estrogen cream is applied daily or an estradiol vaginal ring is put in place. If no resolution occurs after 2 weeks, the nonhealing vaginal mucosa should be biopsied.

Pressure on the rectum or bladder. If the pessary causes significant discomfort or interferes with voiding function, then either a different size or a different type pessary should be tried

Patients may discontinue pessary use for a variety of reasons. Among these are:

- discomfort

- inadequate improvement of POP or incontinence symptoms

- expulsion of the pessary during daily activities

- the patient's desire for surgery instead

- worsening of urine leakage

- difficulty inserting or removing the pessary

- damage to the vaginal mucosa

- pain during removal of the pessary in the office.

\section{FAST \\ TRACK}

For difficult-toremove pessaries or for women physically unable to remove their own ring pessary, the clinician should remove and clean the pessary in the office every 3 to 6 months

CONTINUED ON PAGE 24 
TABLE 1 Percentage of women with relief of POP symptoms with pessary use $e^{4-13}$

\begin{tabular}{|c|c|c|c|}
\hline Study & No. of women & Outcome & Percentage \\
\hline Wu, $1997^{4}$ & 81 & Continued pessary use 12 months & 66 \\
\hline Bai, $2005^{5}$ & 104 & "Satisfied" with pessary use & 70 \\
\hline Clemons, $2004^{6}$ & 72 & "Satisfaction" after pessary use for 2 months & 92 \\
\hline Hanson, $2006^{7}$ & 661 & Relief of POP symptoms & 83 \\
\hline Fernando, $2006^{8}$ & 97 & Success maintaining pessary for 4 months & 48 \\
\hline Cundiff, $2007^{9}$ & 134 & $\begin{array}{l}\text { Relief of symptoms of protrusion and voiding dysfunction } \\
\text { at } 6 \text { months }\end{array}$ & 57 \\
\hline Komesu, $2007^{10}$ & 64 & Continued use $6-12$ months & 56 \\
\hline Yang, $2018^{11}$ & 162 & "Satisfied" after pessary use for 1 year & 79 \\
\hline Mao, $2018^{12}$ & 142 & Successful use of pessary 17 months & 69 \\
\hline Duenas, $2018^{13}$ & 94 & Continuous use, average 27 months & 80.8 \\
\hline
\end{tabular}

TABLE 2 Percentage of women with relief of SUI symptoms with pessary use $e^{6,8,14-17}$

\begin{tabular}{|c|c|c|c|}
\hline Study & No. of women & Outcome & Percentage \\
\hline Clemons, $2004^{6}$ & 73 & SUI improvement after 2 months & 45 \\
\hline Farrell, $2004^{14}$ & 97 & Complete or partial decrease in SUI symptoms at 11 months & 61 \\
\hline Donnelly, $2004^{15}$ & 101 & SUl improvement after 6 months & 50 \\
\hline Fernando, $2006^{8}$ & 97 & SUl improvement after 4 months & 77 \\
\hline Richter, $2010^{16}$ & 149 & SUI improvement after 3 months & 40 \\
\hline Ding, $2016^{17}$ & 31 & SUI improvement after 3 months & 58 \\
\hline
\end{tabular}

Abbreviation: SUI, stress urinary incontinence.

\section{Pessary effectiveness} for POP and SUI symptoms

As might be expected with a device that is available in so many forms and is used to treat varied types of POP and SUI, the data concerning the success rates of pessary use vary considerably. These rates depend on the definition of success, that is, complete or partial control of prolapse and/or incontinence; which devices are being evaluated; and the nature and severity of the POP and/or SUI being treated.

That being said, a review of the literature reveals that the rates of prolapse symptom relief vary from $48 \%$ to $92 \%$ (TABLE 1$)^{4-13}$

As for success in relieving symptoms of incontinence, studies show improvements in from $40 \%$ to $77 \%$ of patients (TABLE 2). ${ }^{6,8,14-17}$

In addition, some studies show a $50 \%$ improvement in bowel symptoms (urgency, obstruction, and anal incontinence) with the use of a pessary. ${ }^{9,18}$

\section{How pessaries compare with surgery}

While surgery has the advantage of being a one-time fix with a very high rate of initial success in correcting both POP and incontinence, surgery also has potential drawbacks: 
- It is an invasive procedure with the discomfort and risk of complications any surgery entails.

- There is a relatively high rate of prolapse recurrence.

- It exposes the patient to the possibility of mesh erosion if mesh is employed either for POP support or incontinence treatment.

Pessaries, on the other hand, are inexpensive, nonsurgical, removable, and allow for immediate correction of symptoms. Moreover, if the pessary is tried and is found to be unsatisfactory, surgery always can be performed subsequently.

Drawbacks of pessary treatment compared with surgery include the:

- ongoing need to wear an artificial internal device

- need for intermittent pessary removal and cleansing

- inability to have sexual intercourse with certain kinds of pessaries in place

- possible accumulation of vaginal discharge and odor.

\section{Sexual activity and pessaries}

Studies by Fernando, Meriwether, and Kuhn concur that for a substantial number of pessary users who are sexually active, both frequency and satisfaction with sexual intercourse are increased. ${ }^{8,19,20}$ Kuhn further showed that desire, orgasm, and lubrication improved with the use of pessaries. ${ }^{20}$ While some types of pessaries do require removal for intercourse, Clemons reported that issues involving sexual activity are not associated with pessary discontinuation. ${ }^{21}$

\section{Using a pessary to predict a surgical outcome}

Because a pessary elevates the pelvic organs, supports the vaginal walls, and lifts the bladder and urethra into a position that simulates the results of surgical repair, trial placement of a pessary can be used as a fairly accurate predictive tool to model what pelvic support and continence status will be after a proposed surgical procedure. ${ }^{22,23}$ This is especially important because a significant number of patients with POP will have their occult stress incontinence unmasked following a reparative procedure. ${ }^{24} \mathrm{~A}$ brief pessary trial prior to surgery, therefore, can be a useful tool for both patient and surgeon.

\section{Pessaries for prevention of preterm labor}

Almost 1 in 10 births in the United States occurs before 37 completed weeks of gestation. ${ }^{25}$ Obstetricians have long thought that in women at risk for preterm delivery, the use of a pessary might help reduce the pressure of the growing uterus on the cervix and thus help prevent premature cervical dilation. It also has been thought that use of a pessary would be a safer and less invasive alternative to cervical cerclage. Many studies have evaluated the use of pessaries for the prevention of preterm labor with a mixture of positive (TABLE 3, page 26) ${ }^{26-29}$ and negative results (TABLE 4, page 26). ${ }^{30-33}$

From these data, it is reasonable to conclude that:

- The final answer concerning the effectiveness or lack thereof of pessary use in preventing preterm delivery is not yet in.

- Any advantage there might be to using pessaries to prevent preterm delivery cannot be too significant if multiple studies show as many negative outcomes as positive ones.

\section{Pessary effectiveness in defecatory disorders}

Vaginal birth has the potential to create multiple anatomic injuries in the anus, lower pelvis, and perineum that can affect defecation and bowel control. Tears of the anal sphincter, whether obvious or occult, may heal incompletely or be repaired inadequately. ${ }^{34}$ Nerve innervation of the perianal and perineal areas can be interrupted or damaged by stretching, tearing, or prolonged compression. Of healthy parous adult women, $7 \%$ to $16 \%$ admit incontinence of gas or feces. ${ }^{35,36}$ In addition, when a rectocele is present,
FAST

TRACK

Trial placement

of a pessary can

be used as a fairly

accurate predictive

tool to model what

pelvic support and continence status

will be after a

proposed surgical

procedure 
TABLE 3 Effectiveness of pessaries to prevent preterm labor ${ }^{26-29}$

\begin{tabular}{l|c|c}
\hline Study & No. of women & Effectiveness \\
\hline Goya, 2012 & 385 & $\begin{array}{c}\text { 4.5-fold lower rate of preterm delivery with pessary use (6\%) } \\
\text { vs expectant management (27\%) }\end{array}$ \\
\hline Di Tommaso, 201627 & 40 & $\begin{array}{c}\text { 30\% less likely to deliver before 36 weeks with use of pessary in twins, } \\
\text { cervical length <2.5 cm between 21 and 31 weeks }\end{array}$ \\
\hline Saccone, 201728 & 300 & $\begin{array}{c}\text { 2-fold lower preterm delivery rate with pessary use and progesterone (7.3\%) } \\
\text { vs progesterone alone (15\%) }\end{array}$ \\
\hline Perez-Lopez, 201929 & 1,612 & $\begin{array}{c}\text { Reduced the rate of spontaneous preterm birth } \\
\text { both at 34 and at 37 weeks (risk ratio, 0.33) }\end{array}$ \\
\hline
\end{tabular}

TABLE 4 Lack of effectiveness of pessaries to prevent preterm labor ${ }^{30-33}$

\begin{tabular}{l|c|c}
\hline Study & No. of women & Effectiveness \\
\hline Hui, 20130 & 108 & $\begin{array}{c}\text { Higher rate of preterm delivery in the pessary group (9.4\%) } \\
\text { than in the control group (5.5\%) }\end{array}$ \\
\hline Nicolaides, 201631 & 931 & $\begin{array}{c}\text { No difference in preventing preterm labor: use of the pessary (12\%) } \\
\text { vs expectant management (10.8\%) }\end{array}$ \\
\hline Saccone, 201732 & 1,420 & $\begin{array}{c}\text { Use of a vaginal pessary did not reduce the rate } \\
\text { of spontaneous preterm delivery or improve perinatal outcomes }\end{array}$ \\
\hline Conde-Agudelo, 202033 & 4,687 (12 studies) & $\begin{array}{r}\text { No significant differences between the pessary and no-pessary groups } \\
\text { in the risk of spontaneous preterm birth <34 weeks }\end{array}$ \\
\hline
\end{tabular}

table 5 Pessary CPT codes $^{38}$

\begin{tabular}{l|c|c}
\hline Diagnosis & CPT code & Notes \\
\hline Pessary fitting & 57160 & Fitting and insertion of pessary \\
\hline Pessary device & A4562 & \\
\hline Evaluation, management-Existing patient & $99211-99215$ & Depending on complexity and length of visit \\
\hline Evaluation, management-New patient & $99201-99205$ & Depending on complexity and length of visit \\
\hline Return visit for follow-up/cleaning & 99213 & E \& M only \\
\hline Abbreviations: CPT, Current Procedural Terminology; E \& M, evaluation and management. & \\
\hline
\end{tabular}

stool in the lower rectum may cause bulging of the anterior rectal wall into the vagina, preventing stool from passing out of the anus. This sometimes requires women to digitally press their posterior vaginal walls during defecation to evacuate stool successfully. The question thus arises as to whether or not pessary placement and subsequent relief of rectoceles might facilitate bowel move- ments and decrease or eliminate defecatory dysfunction.

As with the issue of pessary use for prevention of preterm delivery, the answer is mixed. For instance, while Brazell ${ }^{18}$ showed that there was an overall improvement in bowel symptoms in pessary users, a study by Komesu ${ }^{10}$ did not demonstrate improvement. 
There is, however, a relatively new device specifically designed to control defecatory problems: the vaginal bowel control system (Eclipse; Pelvalon). The silicon device is placed intravaginally as one does a pessary. After insertion, it is inflated via a valve and syringe. It works by putting pressure on and reversibly closing the lower rectum, thus blocking the uncontrolled passage of stool and gas. It can be worn continuously or intermittently, but it does need to be deflated for normal bowel movements. One trial of this device demonstrated a $50 \%$ reduction in incontinence episodes with a patient satisfaction rate of $84 \%$ at 3 months. ${ }^{37}$ This device may well prove to be a valuable nonsurgical approach to the treatment of fecal incontinence. Unfortunately, the device is relatively expensive and usually is not covered by insurance as third-party payers do not consider it to be a pessary (which generally is covered).

\section{Practice management particulars}

Useful information on Current Procedural Terminology codes for pessaries, diagnostic codes, and the cost of various pessaries is provided in TABLE $5,{ }^{38}$ TABLE 6, ${ }^{39}$ and TABLE $7.40-42$

\section{A contemporary device used since antiquity}

Pessaries, considered "old-fashioned" by many gynecologists, are actually a very costeffective and useful tool for the correction of POP and SUI. It behooves all who provide

\section{TABLE 6 Diagnostic codes supporting medical necessity for pessary ${ }^{39}$}

\begin{tabular}{l|c}
\hline Diagnosis & CPT codes \\
\hline Complete uterovaginal prolapse & $\mathrm{N} 81.3$ \\
\hline Cystocele & $\mathrm{N} 81.10$ \\
\hline Rectocele & $\mathrm{N} 81.6$ \\
\hline Stress incontinence & $\mathrm{N} 39.3$ \\
\hline Enterocele & $\mathrm{N} 81.5$ \\
\hline Other female genital prolapse & $\mathrm{N} 81.9$ \\
\hline Abbreviation: CPT, Current Procedural Terminology. & \\
\hline
\end{tabular}

TABLE 7 Cost of various pessaries ${ }^{40-42}$

\begin{tabular}{l|c:c}
\hline Type of pessary & Source & Cost \\
\hline Ring & Milex & $\$ 131$ \\
\hline Ring & CooperSurgical & $\$ 123$ \\
\hline Ring & Online & $\$ 30$ \\
\hline Inflatable & Milex & $\$ 129$ \\
\hline Cube & Milex & $\$ 116$ \\
\hline Cube & CooperSurgical & $\$ 166$ \\
\hline Cube & Online & $\$ 45-\$ 60$ \\
\hline Gellhorn & CooperSurgical/Milex & $\$ 152$ \\
\hline Gellhorn & Online & $\$ 30-\$ 55$ \\
\hline
\end{tabular}

medical care to women to be familiar with them, to know when they might be useful, and to know how to fit and prescribe them.

\section{References}

1. O'Dell K, Atnip S. Pessary care: follow up and management of complications. Urol Nurs. 2012;32:126-136, 145.

2. Gorti M, Hudelist G, Simons A. Evaluation of vaginal pessary management: a UK-based survey. J Obstet Gynaecol. 2009;29:129-131.

3. Meriwether KV, Rogers RG, Craig E, et al. The effect of hydroxyquinoline-based gel on pessary-associated bacterial vaginosis: a multicenter randomized controlled trial. $\mathrm{Am}$ Obstet Gynecol. 2015;213:729.e1-9.

4. Wu V, Farrell SA, Baskett TF, et al. A simplified protocol for pessary management. Obstet Gynecol. 1997;90:990-994.

5. Bai SW, Yoon BS, Kwon JY, et al. Survey of the characteristics and satisfaction degree of the patients using a pessary. Int Urogynecol J Pelvic Floor Dysfunct. 2005;16:182-186.

6. Clemons JL, Aguilar VC, Tillinghast TA, et al. Patient satisfaction and changes in prolapse and urinary symptoms in women who were fitted successfully with a pessary for pelvic organ prolapse. Am J Obstet Gynecol. 2004;190:1025-1029.

7. Hanson LM, Schulz JA, Flood CG, et al. Vaginal pessaries in managing women with pelvic organ prolapse and urinary incontinence: patient characteristics and factors contributing to success. Int Urogynecol J Pelvic Floor Dysfunct. 2006;17: 155-159.

8. Fernando RJ, Thakar R, Sultan AH, et al. Effect of vaginal pessaries on symptoms associated with pelvic organ prolapse. Obstet Gynecol. 2006;108:93-99.

9. Cundiff GW, Amundsen CL, Bent AE, et al. The PESSRI study: symptom relief outcomes of a randomized crossover trial of the ring and Gellhorn pessaries. Am J Obstet Gynecol. 2007;196:405.e1-405e.8.

10. Komesu YM Rogers RG, Rode MA, et al. Pelvic floor symptom changes in pessary users. Am J Obstet Gynecol. 2007;197: 620.e1-6.

11. Yang J, Han J, Zhu F, et al. Ring and Gellhorn pessaries used in 
patients with pelvic organ prolapse: a retrospective study of 8 years. Arch Gynecol Obstet. 2018;298:623-629.

12. Mao M, Ai F, Zhang Y, et al. Changes in the symptoms and quality of life of women with symptomatic pelvic organ prolapse fitted with a ring with support pessary. Maturitas. 2018;117:51-56

13. Duenas JL, Miceli A. Effectiveness of a continuous-use ring shaped vaginal pessary without support for advanced pelvic organ prolapse in postmenopausal women. Int Urogynecol J. 2018;29:1629-1636.

14. Farrell S, Singh B, Aldakhil L. Continence pessaries in the management of urinary incontinence in women. $J$ Obstet Gynaecol Canada. 2004;26:113-117.

15. Donnelly MJ, Powell-Morgan SP, Olsen AL, et al. Vaginal pessaries for the management of stress and mixed urinary incontinence. Int Urogynecol J Pelvic Floor Dysfunct. 2004;15:302-307.

16. Richter HE, Burgio KL, Brubaker L, et al; Pelvic Floor Disorders Network. Continence pessary compared with behavioral therapy or combined therapy for stress incontinence: a randomized controlled trial. Obstet Gynecol. 2010;115:609-617.

17. Ding J, Chen C, Song XC, et al. Changes in prolapse and urinary symptoms after successful fitting of a ring pessary with support in women with advanced pelvic organ prolapse: a prospective study. Urology. 2016;87:70-75.

18. Brazell HD, Patel M, O'Sullivan DM, et al. The impact of pessary use on bowel symptoms: one-year outcomes. Female Pelvic Med Reconstr Surg. 2014;20:95-98.

19. Meriwether KV, Komesu YM, Craig C, et al. Sexual function and pessary management among women using a pessary for pelvic floor disorders. J Sex Med. 2015;12:2339-2349.

20. Kuhn A, Bapst D, Stadlmayr W, et al. Sexual and organ function in patients with symptomatic prolapse: are pessaries helpful? Fertil Steril. 2009;91:1914-1918.

21. Clemons JL, Aguilar VC, Sokol ER, et al. Patient characteristics that are associated with continued pessary use versus surgery after 1 year. Am J Obstet Gynecol. 2004;191:159-164

22. Liang CC, Chang YL, Chang SD, et al. Pessary test to predict postoperative urinary incontinence in women undergoing hysterectomy for prolapse. Obstet Gynecol. 2004;104:795-800.

23. Liapis A, Bakas P, Georgantopoulou C, et al. The use of the pessary test in preoperative assessment of women with severe genital prolapse. Eur J Obstet Gynecol Reprod Biol. 2011; 155:110-113.

24. Wei JT, Nygaard I, Richter HE, et al; Pelvic Floor Disorders Network. A midurethral sling to reduce incontinence after vaginal prolapse repair. $N$ Engl J Med. 2012;366:2358-2367.

25. March of Dimes. Quick facts: preterm birth. https://www marchofdimes.org/Peristats/ViewTopic. aspx?reg=99 \&top=3\&lev=0\&slev=1\&gclid=EAIaIQobChMI4r. Accessed December 10, 2020.

26. Goya M, Pratcorona L, Merced C, et al; PECEP Trial Group Cervical pessary in pregnant women with a short cervix (PECEP): an open-label randomized controlled trial. Lancet. 2012;379:1800-1806
27. Di Tommaso M, Seravalli V, Arduino S, et al. Arabin cervica pessary to prevent preterm birth in twin pregnancies with short cervix. J Obstet Gynaecol. 2016;36:715-718.

28. Saccone G, Maruotti GM, Giudicepietro A, et al; Italian Preterm Birth Prevention (IPP) Working Group. Effect of cervical pessary on spontaneous preterm birth in women with singleton pregnancies and short cervical length: randomized clinical trial. JAMA. 2017;318:2317-2324.

29. Perez-Lopez FR, Chedraui P, Perez-Roncero GR, et al; Health Outcomes and Systematic Analyses (HOUSSAY) Project. Effectiveness of the cervical pessary for the prevention of preterm birth in singleton pregnancies with a short cervix: a meta-analysis of randomized trials. Arch Gynecol Obstet. 2019;299:1215-1231.

30. Hui SYA, Chor CM, Lau TK, et al. Cerclage pessary for preventing preterm birth in women with a singleton pregnancy and a short cervix at 20 to 24 weeks: a randomized controlled trial. Am J Perinatol. 2013;30:283-288.

31. Nicolaides KH, Syngelaki A, Poon LC, et al. A randomized trial of a cervical pessary to prevent preterm singleton birth. N Engl J Med. 2016;374:1044-1052.

32. Saccone G, Ciardulli A, Xodo S, et al. Cervical pessary for preventing preterm birth in singleton pregnancies with short cervical length: a systematic review and meta-analyses. J Ultrasound Med. 2017;36:1535-1543.

33. Conde-Agudelo A, Romero R, Nicolaides KH. Cervical pessary to prevent preterm birth in asymptomatic high-risk women: a systematic review and meta-analysis. Am J Obstet Gynecol. 2020;223:42-65.e2.

34. Sultan AH, Kamm MA, Hudson CN, et al. Anal-sphincter disruption during vaginal delivery. $N$ Engl J Med. 1993;329: 1905-1911.

35. Talley NJ, O'Keefe EA, Zinsmeister AR, et al. Prevalence of gastrointestinal symptoms in the elderly: a population-based study. Gastroenterology. 1992;102:895-901.

36. Denis P, Bercoff E, Bizien MF, et al. Prevalence of anal incontinence in adults [in French]. Gastroenterol Clin Biol. 1992;16:344-350.

37. Richter HE, Matthew CA, Muir T, et al. A vaginal bowelcontrol system for the treatment of fecal incontinence. Obstet Gynecol. 2015;125:540-547.

38. 2019 Current Procedural Coding Expert. Optum360; 2018.

39. ICD-10-CM Expert for Physicians. Optum360; 2019.

40. MDS Medical Department Store website. http://www .medicaldepartmentstore.com/Pessary-Vaginal -Pessaries-/3788.htm?gclid=CjwKCAiAlNf-BRB _Eiw A 2 o s bxdqln 8 fQg - Ax OUEM phM9aYlT Ift Skwy0xXLT0PrcpIZnb5gBhiLc1RoCsbMQAvD_BwE. Accessed December 15, 2020.

41. Monarch Medical Products website. https://www .monarchmedicalproducts.com/index.php?route=product /category\&path=99_67. Accessed December 15, 2020.

42. CooperSurgical Medical Devices website. https://www .coopersurgical.com/our-brands/milex/. Accessed December 15, 2020 